\title{
IMPLEMENTASI METODE WATERFALL DALAM PEMBANGUNAN COMPANY PROFILE WEBSITE AKADEMI KOMUNITAS DHARMA BHAKTI BANGKA (AK DBB)
}

\author{
Ahmat Josi ${ }^{1}$, Sidhiq Andriyanto ${ }^{2}$ \\ ${ }^{1}$ Program Studi Teknologi Rekayasa Perangkat Lunak, Politeknik Manufaktur Negeri Bangka \\ Belitung \\ e-mail: ${ }^{1}$ Ahmatjosi@polman-babel.ac.id , ${ }^{2}$ sidhiq.andriyanto@ polman-babel.ac.id
}

\begin{abstract}
Abstrak
Perkembangan teknologi menuntut perguruan tinggi untuk melakukan inovasi terutama dibidang teknologi informasi, seperti pengembangan aplikasi-aplikasi atau website, website adalah sebuah halaman bermuatan informasi yang ditampilkan oleh sebuah server dan harus diakses bisa diakses secara online. Website Akademi Komunitas Dharma Bhakti Bangka (AK DBB) merupakan sebuah media untuk mempublikasikan data atau informasi terkait dengan kampus AKDBB seperti informasi profil, program studi, prestasi dosen serta mahasiswa, adapun pembangunan website ini menggunakan metode waterfall model, yaitu suatu metode untuk mengembangkan sistem yang dimulai dari tahap Melakukan Komunikasi (Communication), Planning (Estimating, Scheduling, Tracking), Modeling (Analysis \& Design), Construction (Code $\&$ Test),Deployment (Delivery, Support, Feedback).
\end{abstract}

Kata kunci : AK DBB; Website; Company; Profile; Waterfall; Model

\begin{abstract}
Technological developments require universities to make innovations, especially in the field of information technology, such as developing applications or websites, a website is a page containing information displayed by a server and must be accessed online. The Dharma Bhakti Bangka (AK DBB) Community Academy website is a medium for publishing data or information related to the $A K D B B$ campus such as profile information, study programs, lecturer and student achievements, while the construction of this website uses the waterfall model method, which is a method for developing a system starting from the stage of Communication (Communication), Planning (Estimating, Scheduling, Tracking), Modeling (Analysis \& Design), Construction (Code \& Test), Deployment (Delivery, Support, Feedback).
\end{abstract}

Keywords : AK DBB; Website; Company; Profile; Waterfall; Model

\section{PENDAHULUAN}

Meningkatnya kebutuhan inovasi dan teknologi mendorong manusia untuk berlomba untuk mengembangkan teknologi baru agar pengolahan data dan informasi dapat dilakukan dengan mudah dan cepat [1], peningkatan teknologi tersebut mempengaruhi efisiensi waktu dan penghematan biaya. pada dasarnya teknologi komputer digunakan sebagai alat bantu seperti mengolah, menyimpan, dan mengambil kembali data atau informasi yang diperlukan. diberbagai instansi pemerintah maupun swasta termasuk instansi pendidikan seperti sekolah-sekolah ataupun perguruan tinggi Perguruan tinggi adalah lembaga ilmiah yang mempunyai tugas menyelenggarakan pendidikan, pengajaran diatas perguruan tingkat menengah, dan yang memberikan pendidikan dan pengajaran berdasarkan kebudayaan kebangsaan indonesia dan dengan cara ilmiah [2] didalam mengemban tugas tersebut banyak perguruan tinggi berusaha selalu mengingkatkan kualitasnya 
termasuk Akademi komunitas dharma bhakti bangka.

Akademi Komunitas Dharma Bhakti

Bangka (AK DBB) adalah satuan pendidikan tinggi yang menyelenggarakan jenjang pendidikan vokasi setingkat diploma satu dan/atau diploma dua dalam satu atau beberapa cabang ilmu pengetahuan dan/atau teknologi tertentu yang berbasis keunggulan lokal atau untuk memenuhi kebutuhan khusus. Akademi Komunitas Dharma Bhati Bangka (AK DBB) merupakan perguruan tinggi yang diselenggarakan oleh masyarakat yang berada di bawah naungan Yayasan Sejahtera Bhakti Dharma Sentosa (YSBDS). AK DBB beralamat di Kecamatan Pemali Kabupaten Bangka Propinsi Kepulauan Bangka Belitung. Pembinaan AK DBB dilakukan oleh Direktur Jenderal Pendidikan Tinggi melalui Koordinasi, Perguruan Tinggi Swasta (KOPERTIS) Wialayah II Palembang, Universitas Bangka Belitung, dan Yayasan Sejahtera Bhakti Dharma Sentosa.

Saat ini akademi komunitas dharma bhakti sudah menggunakan teknologi komputer dalam proses adminstrasi namun untuk proses publikasi atau penyebaran informasi kampus akademi komunitas dharma bhakti bangka masih menggunakan cara manual yaitu menggunakan pamplet, brosur dan beberapa cara yang masih terbilang kurang efektif, hal ini menyebabkan proses penyebaran infromasi tentang kampus menjadi lambat, dan susah untuk diakses, apalagi saat ini perkembangan internet dan gadget dan komputer sangat pesat, untuk mengatasi hal tersebut diperlukan sebuah media yang dapat membantu akademi komunitas dharma bhakti bangka dalam mempublikas informasi tentang kampus, salah satunya ialah website (company profile website).

Website atau situs dapat diartikan sebagai kumpulan halaman yang menmpilkan informasi data teks, data gambar diam atau gerak, data animasi,suara,video dan gabungan dari semuanya baik yang bersifat statis maupun dinamis yang membentuk suatu rangkaian bangunan yang salingterkait dimana masingmasing dihubungkan dengan jaringanjaringan halaman (hyperlink) [3]. ada banyak metode pengembangan sistem yang bisa digunakan untuk membangun website misalnya metode RAD, Prototipe, Ekstrime Programing dan metode Waterfall model.

Model waterfall adalah model klasik yang bersifat sistematis, berurutan dalam membangun software. Nama model ini sebenarnya adalah "Linear Sequential Model". Model ini sering disebut juga dengan "classic life cycle" atau metode waterfall. Model ini termasuk ke dalam model generic pada rekayasa perangkat lunak dan pertama kali diperkenalkan oleh Winston Royce sekitar tahun 1970 sehingga sering dianggap kuno, tetapi merupakan model yang paling banyak dipakai dalam Software Engineering (SE). Model ini melakukan pendekatan secara sistematis dan berurutan. Disebut dengan waterfall karena tahap demi tahap yang dilalui harus menunggu selesainya tahap sebelumnya dan berjalan berurutan Waterfall [4].

\section{TINJAUAN PUSTAKA}

\subsection{Website}

website adalah sebuah halaman berisi informasi yang dapat dilihat jika komputer anda terkoneksi dengan internet". Dengan adanya website semua orang di dunia bisa mendapatkan dan mengelola informasi dengan berbagai sumber yang tersedia di internet. Website sendiri saat ini bisa memuat berbagai macam media, mulai dari teks, gambar, suara bahkan video [5]. selain itu Website sendiri dapat diartikan sebagai suatu alamat yang berfungsi sebagai tempat penyimpanan data dan informasi dengan berdasarkan topik tertentu. Web adalah sistem hypertext, terdiri dari jutaan halaman 
teks yang dihubungkan oleh hyperlinkhyperlink.

Dijelaskan Adapun Jenis-Jenis website terbagi menjadi tiga yaitu sebagai berikut :

\section{a. Website Statis}

Website Statis adalah web yang mempunyai halaman tidak berubah. artinya adalah untuk melakukan perubahan pada suatu halaman harus dilakukan secara manual yakni dengan mengedit code yang menjadi struktur dari situs tersebut

b. website dinamis

website dinamis adalah web yang secara struktur diperuntukan untuk update sesering mungkin. biasanya selain utama yang bisa diakses oleh user pada umumnya juga disediakan halaman admin untuk mengedit konten

c. website interaktif

website interaktif adalah web yang dapat digunakan untuk interaksi, misalnya blogspot, wordpres, media web chat dan lain-lain

\subsection{Html (Hyper Text Markup Language) \\ HTML singkatan dari Hyper Text} Markup Language, yaitu skrip yang berupa tag-tag untuk membuat dan mengatur struktur website (Abdulloh, 2015). Beberapa tugas utama HTML dalam membangun website diantaranya sebagai berikut:

1. Menentukan layout website.

2. Memformat text dasar seperti pengaturan paragraf, dan format font.

3. Membuat list.

4. Membuat tabel.

5. Menyisipkan gambar, video, dan audio.

6. Membuat link.

7. Membuat formulir.

\section{METODOLOGI PENELITIAN}

Metode penelitian yang digunakan untuk pengembangan sistem ini ialah Waterfall Model, adapun tahapan dari metode ini ialah :

\subsection{Melakukan \\ Komunikasi \\ (Communication)}

Pada tahap ini, peneliti melakukan komunikasi dengan customer dalam hal ini pihak AKDBB, demi memahami dan mencapai tujuan yang ingin dicapai. Hasil dari komunikasi tersebut adalah inisialisasi proyek seperti menganalisis permasalahan yang dihadapi dan mengumpulkan data-data yang diperlukan, serta membantu mendefinisikan fitur dan fungsi dari aplikasi.

\subsection{Planning}

Tahap berikutnya adalah tahapan perencanaan yang menjelaskan tentang estimasi proses pengerjaan sistem.

Tabel 1. Rencana Kegiatan

\begin{tabular}{|c|c|c|c|c|c|c|c|c|c|c|c|}
\hline \multirow[t]{2}{*}{$\mathrm{NC}$} & \multirow[t]{2}{*}{ JENIS KEGIATAN } & \multicolumn{10}{|c|}{ BULAN (Naret-Desember) } \\
\hline & & & 04 & 05 & 6 & 97 & 08 & 09 & 10 & & 12 \\
\hline 1 & Persiapan & & & & & & & & & & \\
\hline 2 & Studi Literatur & & & & & & & & & & \\
\hline 3 & Analisa dan desain sistem & & & & & & & & & & \\
\hline 4 & Coding & & & & & & & & & & \\
\hline 5 & Uji Coba dan Analisisis Hasil & & & & & & & & & & \\
\hline
\end{tabular}

\subsection{Modeling (Analysis \& Design)}

Tahapan ini adalah tahap perancangan dan pemodelan arsitektur sistem yang berfokus pada perancangan struktur data, arsitektur software, tampilan interface, dan algoritma program. Tujuannya untuk lebih memahami gambaran besar dari apa yang akan dikerjakan. 
1 Use Case Diagram

Diagram use case atau use case diagram menyajikan interaksi antara use case dan aktor. Aktor dapat berupa orang, peralatan atau system lain yang berinteraksi dengan system yang sedang dibangun. Use case menggambarkan fungsionalitas system atau persyaratan-persyaratan yang harus dipenuhi system dari pandangan pemakai. Use case diagram dapat dilihat pada gambar berikut.

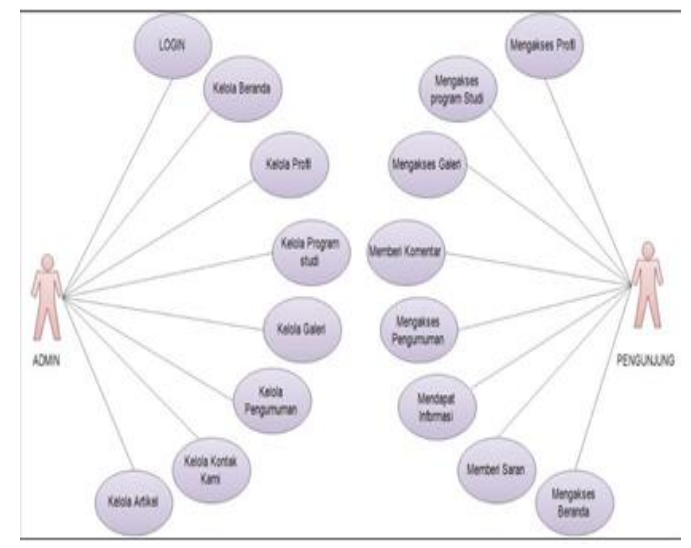

Gambar 1 Usecase Diagram

\section{Class diagram}

Diagram class atau class diagram menunjukan interaksi antar kelas dalam system. Kelas mengandung informasi dan tingkah laku (behavior) yang berkaitan dengan informasi tersebut. Sebuah kelas pada diagram kelas dibuat untuk setiap tipe objek pada diagram sequensial

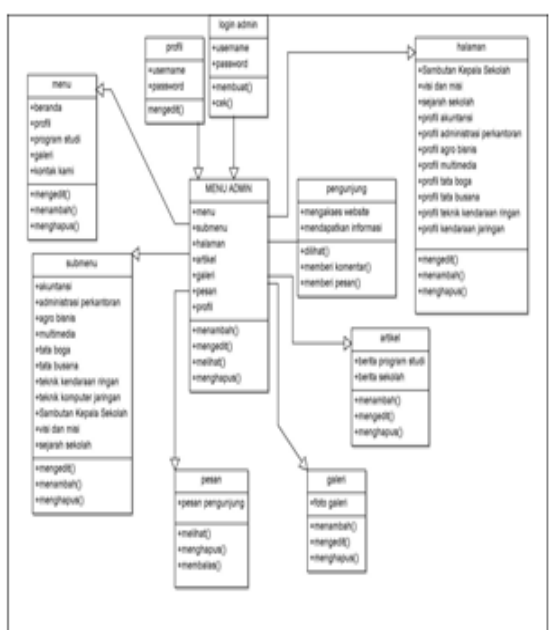

Gambar 2 Class Diagram

\subsection{Construction (Code \& Test)}

Tahapan ini merupakan proses penerjemahan bentuk desain menjadi kode atau bentuk bahasa yang dapat dibaca oleh mesin. Setelah pengkodean selesai, dilakukan pengujian terhadap sistem dan juga kode yang sudah dibuat. Tujuannya untuk menemukan kesalahan yang mungkin terjadi untuk nantinya diperbaiki. Berikut Contoh Penerjemahan bentuk desain ke coding.

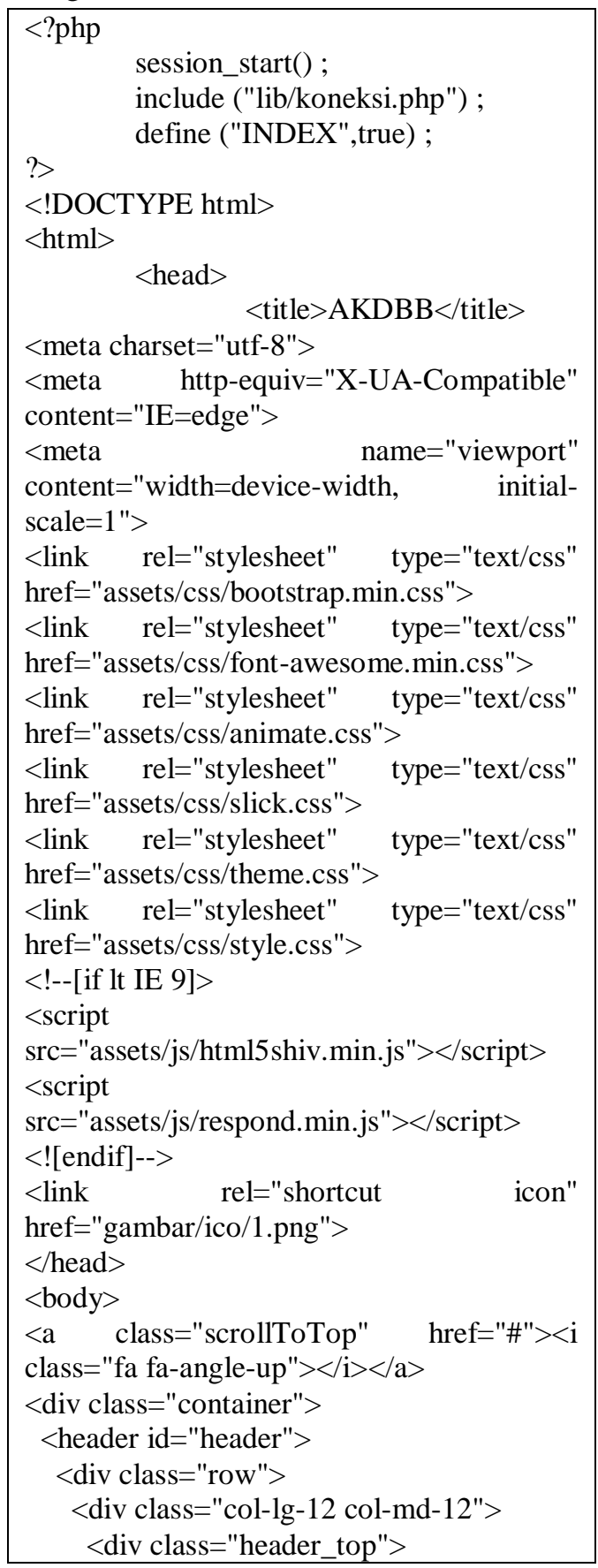




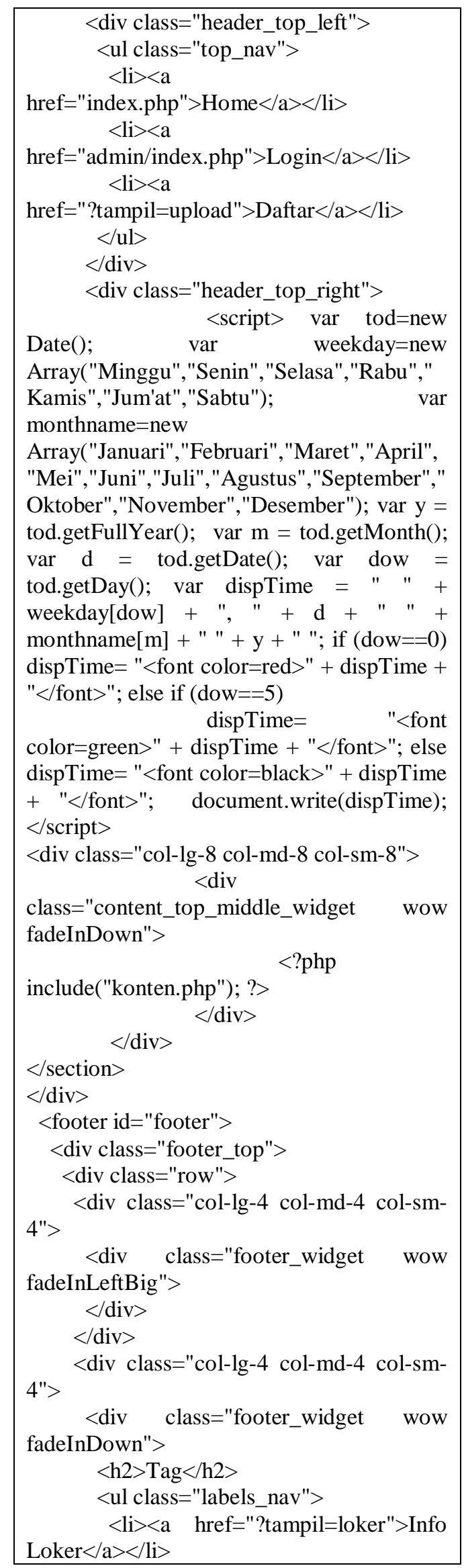

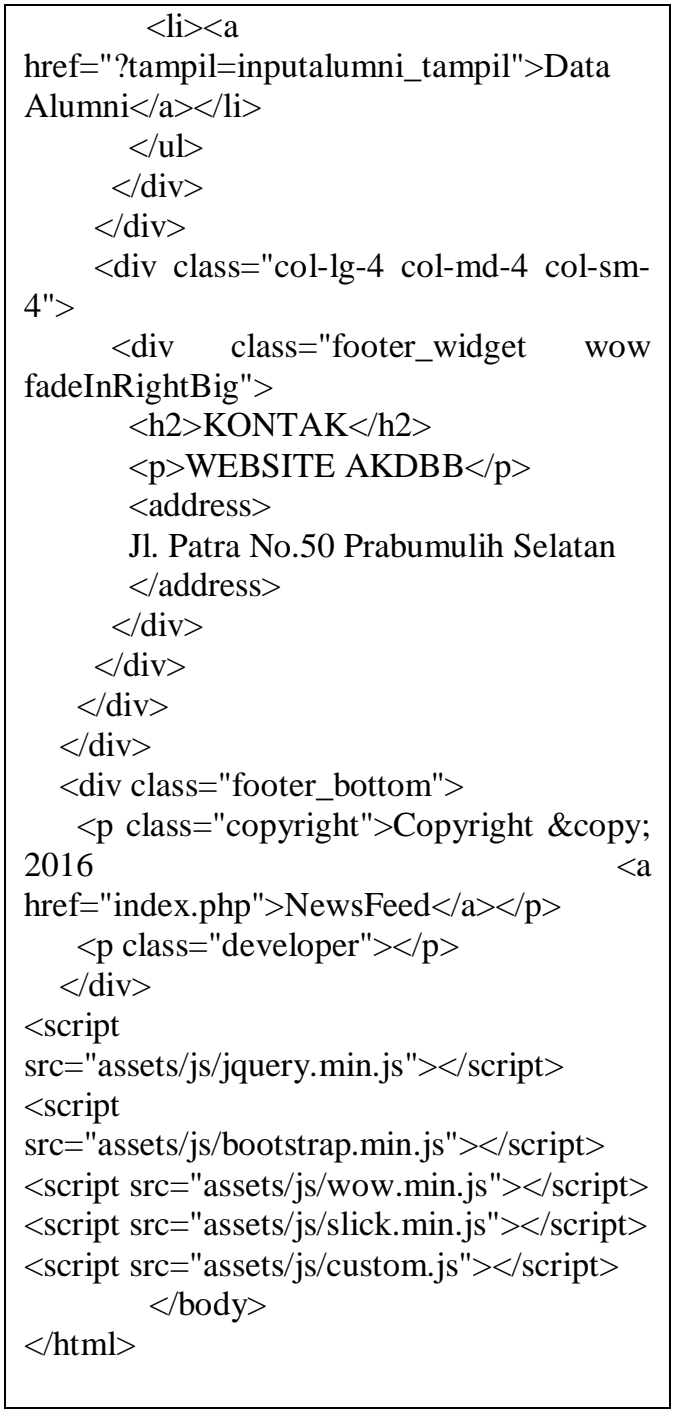

\subsection{Deployment}

Tahapan terakhir ini merupakan tahapan implementasi code kedalam bentuk website dan kemudian dilakukan uji coba ddengan mitra, dalam hal ini pihak kampus (AKDBB), setelah websitenya selesai maka akan diserahkan ke pihak mitra. berikut hasil Deployment website akdbb 


\section{HASIL DAN PEMBAHASAN}

\section{Halaman utama}

Halaman utama merupakan halaman awal yang tampil saat website di akses.

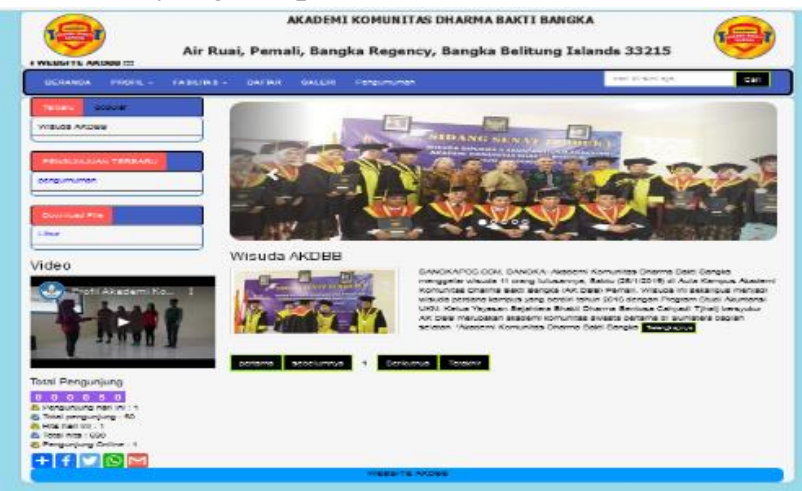

\section{Gambar 3 Halaman utama}

\section{$2 \quad$ Halaman Visi-misi}

Halaman visi-misi meruapakan halaman informasi yang digunakan untuk memberikan informasi tentang visi-misi dari kampus akdbb.

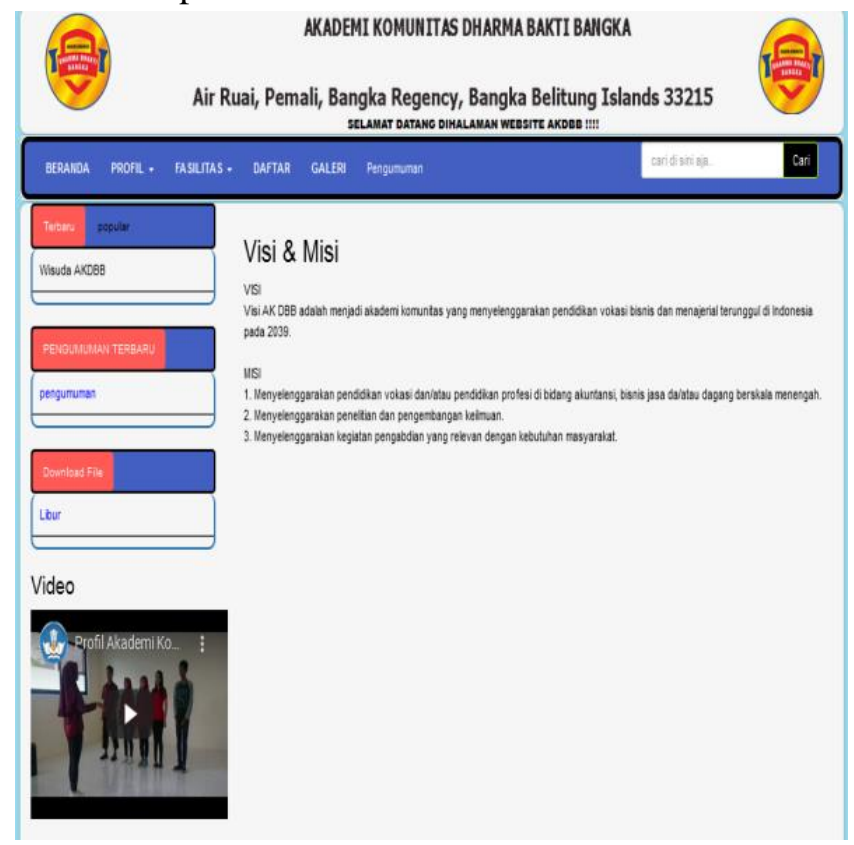

Gambar 4 Halaman visi-misi

\section{Halaman Daftar}

Halaman daftar merupakan halaman yang digunakan untuk calon mahasiswa baru untuk melakukan registrasi atau pendaftaran secara online

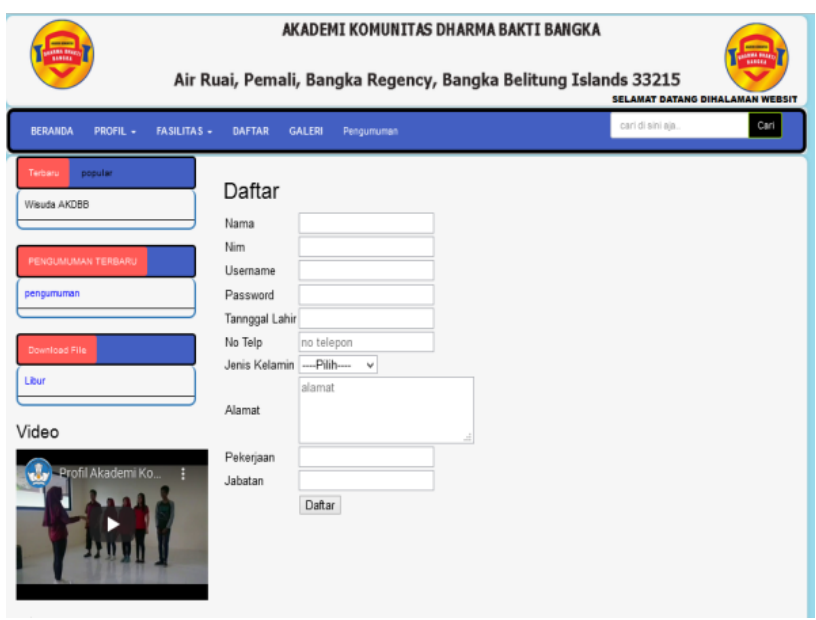

Gambar 5 Halaman daftar

\section{Halaman login admin}

Halaman login admin merupakan halaman utama admin untuk melakukan login ke sistem, yang digunakan untuk mengelola website akdbb.

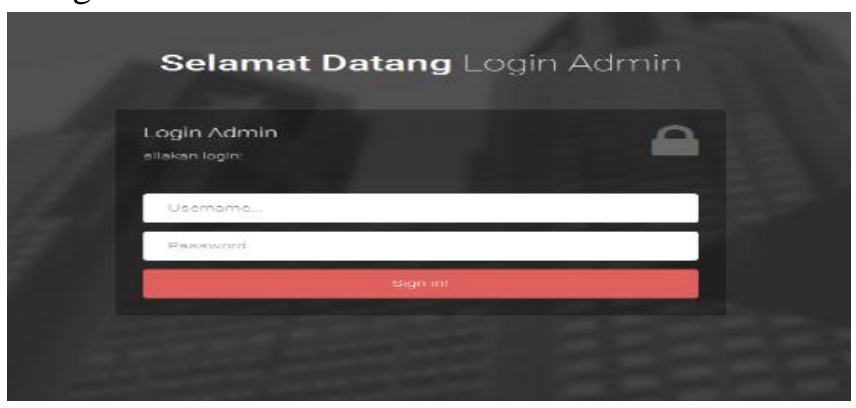

Gambar 6 Halaman login admin 


\section{$5 \quad$ Halaman utama admin}

Halaman utama admin merupakan halaman utama saat admin masuk ke website, halaman ini hanya bisa diakses oleh admin kampus, bukan diperuntukan untuk umum.

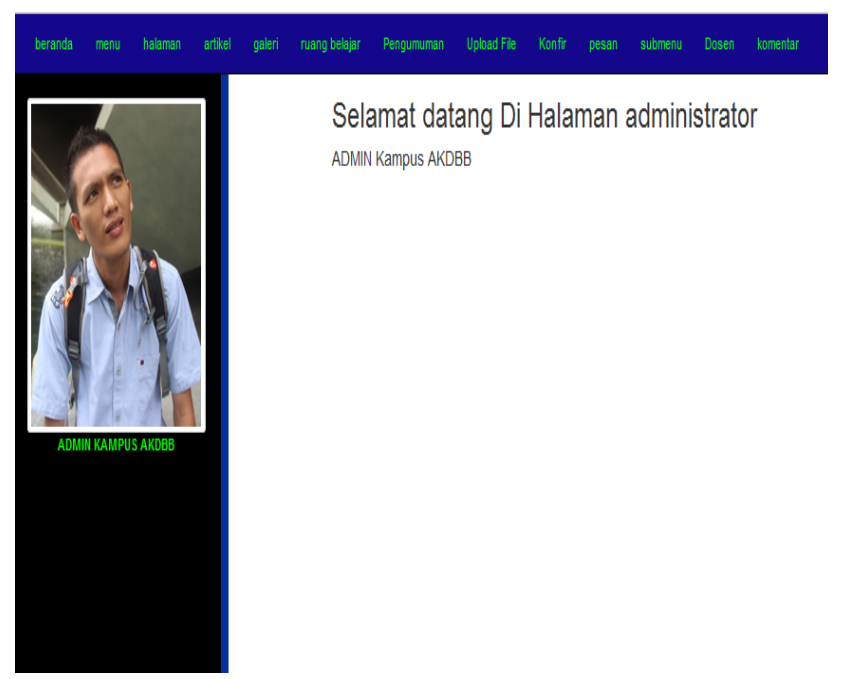

Gambar 7 Halaman utama admin

\section{Halaman admin pengelola}

Halaman admin pengelola merupakan halaman dimana admin dapat melakukan pengelolaan

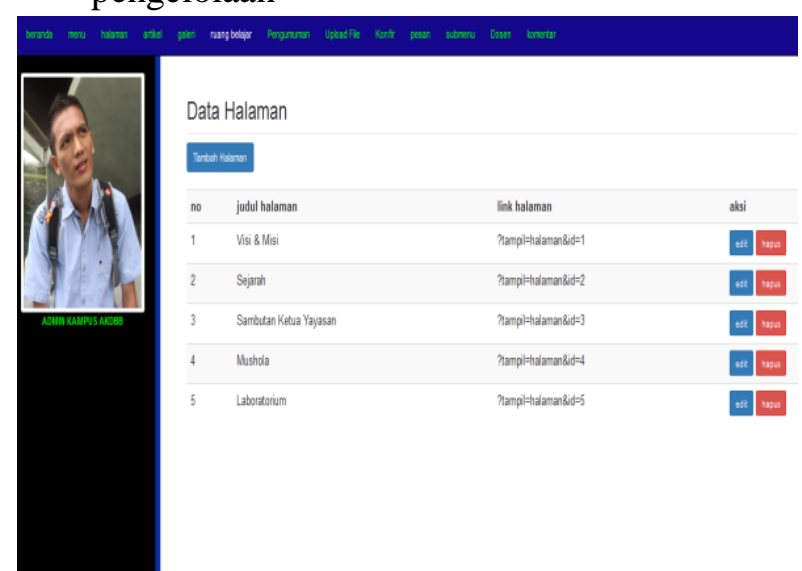

Gambar 8 Halaman Pengelola

\section{Halaman Pengumuman}

Halaman pengumuman adalah halaman untuk admin melakukan upload pengumuman.

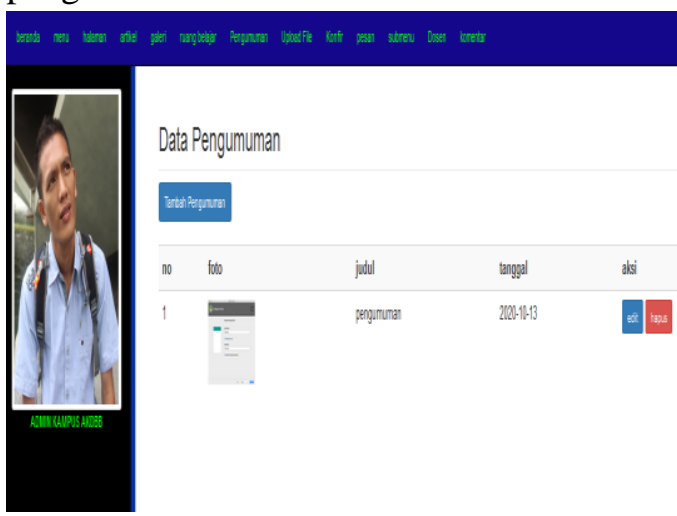

Gambar 9 Halaman Pengumuman

\section{Halaman Galeri}

halaman galeri adalah halaman admin untuk mengupload galeri foto kegiatan

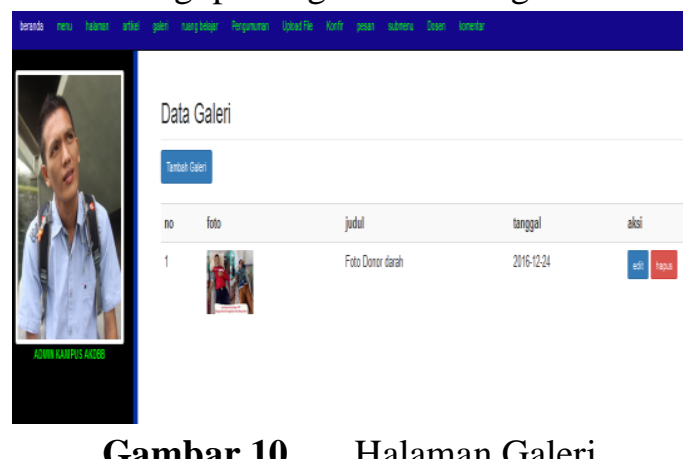

\section{KESIMPULAN}

Adapun kesimpulan dari pembuatan Website AKDBB ini adalah sebagai berikut

1. Website AKDBB ini telah di bangun menggunakan framework bootstrap agar tampilan website menjadi responsive mengikuti platform yang digunakan pengunjung.

2. Mempermudah masyarakat dalam mencari informasi yang berhubungan dengan AKDBB

3. Metode yang digunakan dalam pembangunan website ini menggunakan waterfall model 


\section{SARAN}

Dari pembuatan website AKDBB ini, berikut ini ada beberapa saran yang mungkin dapat menjadi bahan pertimbangan dalam upaya meningkatkan kualitas website dimasa yang akan datang diantaranya yaitu:

1. Perlunya pelatihan terhadap admin yang akan mengelola website.

2. Pemeriksaan panel pada hosting sebaiknya dilakukan secara berkala untuk mengetahui penggunaan data pada website.

\section{DAFTAR PUSTAKA}

[1] A Josi, Abdillah LA, Suryayusra, 2014. Penerapan Teknik Web Scraping Pada Mesin Pencari Artikel Ilmiah. Jurnal Sistem Informasi(SISFO) Vol 5, No 2

[2] Undang-Undang Tentang Perguruan Tinggi, UU RI No 22 Tahun 1961

[3] Riyadi, Retnandi E, Deddy A, 2012. Perancangan sistem informasi berbasis website subsistem guru di sekolah pesantren persatuan islam 99 rancabango.. Jurnal Algoritma Vol 09, No 40

[4] Pressman, R.S. (2015). Rekayasa Perangkat Lunak: Pendekatan Praktisi Buku I. Yogyakarta: Andi

[5] Hernita, 2010. Membangun Website Tanpa Modal. Yogyakarta : Andi Offset. 